\title{
NORMAS PARA LA PUBLICACIÓN DE RESEÑAS
}

Se considerarán para publicación en Revista Iberoamericana aquellas reseñas originales -en español o portugués, sobre libros de crítica literaria y cultural latinoamericana- que cumplan con las siguientes normas editoriales:

1) Revista Iberoamericana no publica reseñas que no hayan sido solicitadas por el director de la sección.

2) Todas las reseñas son sometidas a un proceso de evaluación anónimo.

3) Los libros reseñados no pueden tener más de tres años de antigüedad en relación con el número de la Revista en el que aparecerá publicada la reseña.

4) El objetivo de la reseña es dar una opinión fundamentada sobre el texto reseñado. Por lo tanto, no debe limitarse a ser una mera descripción del contenido. Las apreciaciones, sean positivas o negativas, deben estar debidamente fundamentadas. Cualquier crítica debe estar dirigida al contenido del libro y no hacia el autor. La reseña debe ser adecuadamente equilibrada y balanceada.

5) Para un libro de autor individual, la reseña debe tener entre 900 y 1200 palabras. Para libros colectivos y antologías críticas con múltiples autores, la reseña puede tener entre 1100 y 1500 palabras. Las reseñas que no respeten esta extensión serán devueltas.

6) Se debe evitar citar excesivamente el libro reseñado y no se puede citar la investigación propia. Las citas en inglés deben contar con su traducción al español o portugués entre paréntesis.

7) Es imprescindible que toda la información consignada sea correcta. Se debe tener en cuenta que los evaluadores y/o correctores no tendrán una copia del libro para verificar fechas, números de páginas y la exactitud de las citas. Si la reseña es aceptada, se harán correcciones de estilo si fuera necesario.

8) La reseña debe ser enviada en un plazo de 60 días desde la recepción del libro.

9) Las opiniones expresadas en las reseñas publicadas por el IILI pertenecen a su autor, quien será el único responsable de las mismas. 
Los socios del Instituto que desean servir como reseñadores, por favor, envíen un mensaje electrónico al Prof. Luciano Martínez. El mensaje debe indicar cuál es su área de especialización dentro de la literatura y los estudios culturales latinoamericanos.

Elobjetivo de Revista Iberoamericana es establecer un grupo variado de reseñadores que reflejen la pluralidad de miradas críticas, contextos institucionales y geográficos que caracterizan al IILI. Se busca, asimismo, que la sección se convierta en un punto de consulta obligado sobre las publicaciones más recientes producidas en el campo.

LUCIANO MARTíNEZ

Swarthmore College

Director de Reseñas

Revista Iberoamericana

lmartin1@swarthmore.edu

Las editoriales interesadas en que sus libros sean considerados para ser reseñados, por favor, enviarlos a:

Instituto Internacional de Literatura Iberoamericana (IILI)

c/o Reseñas

1312 Cathedral of Learning

University of Pittsburgh

Pittsburgh, PA 15260, U.S.A.

Por cuestiones de espacio, cronograma editorial y logística, no todos los libros recibidos podrán ser reseñados. Los libros recibidos no son devueltos. 